\title{
What suppliers seek from their downstream buyers.
}

\begin{abstract}
The results of a study undertaken in the Western Australian apple industry suggest that what growers want from their downstream buyers and what they actually receive as a result of their transactions with their preferred trading partners are vastly different. While most growers want a return that is commensurate with the effort they put in, the prices offered by market intermediaries generally leave the growers dissatisfied. In order to reduce the risk and the uncertainty associated with the exchange, growers will invariably seek to establish long-term relationships with preferred trading partners. However, many customers prefer to maintain arms-length transactions and seem generally unwilling to provide the growers with either market information or technical advice.
\end{abstract}

Keyword: Buyer selection; Buyer-supplier relationships; Fruit industry. 